\title{
Childhood Bronchial Asthma and Quality of Life
}

\author{
Hala Elgrawany*, Amel I Ahmed**
}

\begin{abstract}
Asthma is the most common chronic disease in children, which restricts their physical, emotional, and social aspects of life. In North African countries including Egypt, asthma has a major negative impact on the daily activities of asthmatic children. It is approved that the assessment of quality of life (QOL) of asthmatic children is important for enhancing communication between health care providers and patient and it helps in monitoring of treatment. In developing countries, there are not enough data regarding the issue of quality of life especially among asthmatic children. A case control study design was used to investigate the quality of life among asthmatic children compared to non-asthmatic children at Mansoura city, Dakahlia, Egypt. The study included a total number of 392 children (196 children for each study and control group) who were interviewed at the outpatient clinic of Mansoura Chest Hospital. Socioeconomic level of the children's family was determined based on the scoring system of Fahmy and El- Sherbini. A 5-point likert scale was developed according to the World Health Organization "Measurement of Quality of life in children". The study findings revealed a significant poor level of quality of life in relation to physical domain among the asthmatic children compared to non-asthmatic children. Severity of asthma showed a negative significant correlation with the level of quality of life in relation to the three domains. In conclusion, suffering from bronchial asthma negatively affects the children's quality of life, therefore there is a need special attention to provide information about measures to reduce daily activities restrictions.
\end{abstract}

Key words: Quality of Life; Asthmatic Children; Socioeconomic; Severity of Asthma

\section{INTRODUCTION}

Bronchial asthma affects around 300 Petersburg, and 9\% among children million people throughout the world ${ }^{(1,2)}$. in Spain ${ }^{(3,4)}$. In Tehran physician-

The prevalence of asthma is high in western countries and has been rising throughout the late $20^{\text {th }}$ century. It was estimated that the prevalence of asthma was $7.4 \%$ among children in confirmed asthma was reported in $2.1 \%$ of the $6-7$ year olds and $2.6 \%$ of the 13 14 age group. ${ }^{(5)}$ The mean prevalence of asthma among Middle East countries and North African countries is $5.8 \%$ and

\footnotetext{
${ }^{*}$ Assistant Prof. Child Health Kinder Garten Collage University of Alexandria

${ }^{* *}$ Lecturer of Community Health Nursing, Faculty of Nursing, Mansoura University
} 
$3.9 \%$ respectively in Egypt, bronchial disease, providing information about asthma is affecting about $8.2 \%$ of how the condition affects everyday children aged 3-15 years. ${ }^{(6)}$ While the functioning and well-being. ${ }^{(12)}$ Current physician-diagnosed asthma was $9.4 \%$, ability to treat children with chronic in Cairo( ${ }^{(7)}$. disease, coupled with the inability to offer

Asthma is the most common chronic disease in children in developed countries that requires a considerable amount of health and social resources, as it is a heavy burden both for patients and their families and for society as well (8). Asthma is the most common chronic pediatric disease that results in variable restriction in physical, emotional, and social aspects of the child's lif $\mathrm{e}^{(9)}$. It was found that asthma has a major impact on children's lives in Maghreb, and one in four of Egyptian children is unable to attend school regularly because of poor asthma control $(10,11)$.

Quality of life (QOL) is a concept including the child and parents' absolute cure, raises the issue of the quality of life of these children. ${ }^{(13)}$

The assessment of QOL among children gives a better understanding on the children's feelings on their condition, and in enhancing communication between clinicians and patients that helps in the monitoring of treatment, in combination with clinical measures ${ }^{(9,14)}$.

Asthma is known to reduce the quality of life of its sufferers; however, there are no appropriate measures to estimate quality of life in developing countries with diverse cultural beliefs, and values (15). Accordingly, the present study aims to investigate the quality of life among asthmatic children compared to nonsubjective experience with the asthmatic children at Mansoura city. 


\section{Subjects and methods}

Study design: Case control study design was used to explore the quality of life in asthmatic children compared to non- asthmatic children.

\section{Study Setting:}

The study was conducted at the outpatient chest clinic of chest hospital, affiliated to Ministry of Health at Mansoura city.

\section{Study population and size:}

Children who attended this clinic and fulfilling the study inclusion criteria were included.

The inclusion criteria of study participants are:

- The children involved in the study group should be free from any other disease rather than bronchial asthma

- Child age ranges from 3-12years old

- Children who were selected for control group from the outpatient clinic of the same hospital. They were matched to have the same criteria of age, and health condition of the study group rather than to be free from bronchial asthma. Sample size was calculated to be 196 asthmatic children and 196 control according to Fleiss 1981 by using Epiinfo statistical package version 6.00. ${ }^{(16)}$

\section{Study tools}

\section{1- A pre-designed interview sheet}

Interview sheet was used to collect the following data from the child and or his/her parents:

1. Personal data: including age, sex, and socioeconomic data included education and occupations of Parents, crowding index and income. The socioeconomic level of the children's family was determined based on the scoring system of Fahmy and El- Sherbini (1983) $)^{(17)}$. 
The total score ranged from 5 to 19 . expert. The developed scale is a 5 -point Those with scores 15 or more (equal likert scale included 25 items that $80 \%$ of total score) were considered measure three main domains namely: of high socioeconomic class, physical, psychosocial and environment scores $11-14 \quad(60-<80 \%)$ of domains. The total scores of the scale middle socioeconomic class are 110 scores. and scores $<11(<60 \%)$ of - Physical domain included eight items low socioeconomic class. to measure how asthma interferes

2. Disease characteristic: including with physical activities mobility, daily severity of asthma in last four functions and sleep pattern. This domain weeks, according to the report of gained 40 scores

National Heart, Lung and Blood - Psychosocial domain included eight Institute (2007) ${ }^{(18)}$. items to measure interaction with

\section{2- Quality of life scale}

Assessment quality of life's scale was developed according to the World Health Organization "Measurement of Quality of life in children" 1994 and The World Health Organization Quality of Life (WHOQOL)-BREF 2004(19,20). An Arabic version was developed by the researchers and than tested by forward and backward translation by a bilingual how much they are "satisfied" or

- Environment domain included six items to measure safety and healthy living environment at home and school in addition to availability of food preferences, this domain gained 30 scores.

Participants were asked to indicate 
"bothered" with their life or how much asthma symptoms prevent them from doing activities in the last four weeks.

The quality of life degree calculated for each domain and for allover quality of life scores as following:

Poor quality of life $=<60 \%$

Good quality of life $=\geq 60 \%$

\section{Methods:}

\section{1-Administrative process and} ethical considerations:

a- Official permission was obtained from Mansoura Chest Hospital which is affiliated to Ministry of Health, to collect data from outpatient clinic.

b- Written consent was obtained from child's parents to enroll their children in the study. They were informed that all the obtained information would be analyzed anonymously and will be considered as confidential information.

2-Development of the study tool:

a- The researchers developed the interview sheet and Arabic version of quality of life measuring scale after reviewing recent literatures.

b- Validity of the developed tools was tested by 4 experts in the field of pediatrics and community health.

c- A pilot study was carried out on 15 children chosen randomly from the same outpatient clinic to ensure the clarity of the tools.

d- Reliability of the scale was statistically tested by using alpha model test and the unrealistic questions were omitted.

\section{3-Data collection:}

Data collection was conducted during the period from March to April 2009 through interviewing of children with bronchial asthma attending the Outpatient Chest Clinic. Two visits per week were done to the Outpatient Chest Clinic.

\section{Statistical analysis:}

SPSS package (version 0.13) was 
used for the statistical analysis of the obtained data. Chi square test was used to illustrate the difference between asthmatic and non- asthmatic children regarding to their demographic characteristic and different quality of life items. Spearman test was used to estimate the correlation between the quality of life scores of each domain and the socioeconomic level and the degree of asthma.

\section{Results:}

Table 1 shows insignificant difference between asthmatic children and non asthmatic children regarding to their socio-demographic characteristics.

Preschool age children (3-<6 years old) constitute $36.3 \%$ of non -asthmatic children and $45.9 \%$ of asthmatic children, while males children constitute nearly two thirds of both groups. Most of children included in the study live in urban community, and nearly half of them are belonging to the low middle social class.

Table 2 shows that nearly two thirds of asthmatic children suffered from mild intermittent bronchial asthma and only $6.6 \%$ suffered from sever persistent attacks during the last six months.

Results in table 3 describe the distribution of studied children according to their quality of life. There was a significant difference between asthmatic and non- asthmatic children in relation to several issues of quality of life. Most of asthmatic children (89.5\%) reported that pain prevent them from doing what they need to do and (58.2\%) of them depend very much on medical treatment to function daily activities compared to (3.5\%) and no one of non- asthmatic children respectively.

Regarding to the extension of healthy environment that child lives in, $26 \%$ of asthmatic children found their 
living environment to be little healthy environment compared to $11 \%$ of nonasthmatic children. Furthermore, 18.8\%, $4.5 \%, 16.8 \%$ and $2.6 \%$ of asthmatic children were dissatisfied with their sleep pattern, performance of daily activities, food choice, and ability of playing, compared to $0 \%, 2 \%, 5.5 \%$, and $0 \%$ of non- asthmatic children respectively.

Data in table 4 demonstrates the difference between asthmatic and nonasthmatic children in relation to their quality of life's level. Poor level of physical domain was more likely to be observed among $17.3 \%$ of asthmatic children compared to only $3.6 \%$ of nonasthmatic children (OR $0.18, \mathrm{Cl} 95 \%$ 0.076: $0.41 P \leq 0.05)$ the difference was significant. On the other hand, psychosocial and environmental quality of life's domains showed slight insignificant difference between the two groups. Poor level of psychosocial quality of life was found among $16.3 \%$ of asthmatic children compared to $13 \%$ of non- asthmatic children (OR $0.64 \mathrm{Cl} 95 \%$ 0.36: 1.2).

A negative significant correlation observed between the degree of asthma and the level of quality of life in relation to the three domains, while a positive significant correlation was found between the socioeconomic class and environmental domain.

\section{Discussion}

Asthma is one of the most common chronic diseases worldwide that constitutes a considerable health problem among children. (2) Grading of bronchial asthma severity usually indicates that the largest percentage of asthmatic children suffering from moderate or intermittent asthma and a small numbers suffer from severe asthma. In a Turkish study, the intermittent asthma was reported among 
$82 \%$ of asthmatic children and only $7 \%$ had persistent asthma(21) This confirm the findings of the present study which found that $63.8 \%$ suffered from intermittent asthma with less prevalence of persistent asthma either mild, moderate or sever attacks.

All over the world, asthmatic children has lower physical abilities and suffering from sleep disturbance more than their non-asthmatic peers. Asthmatic children describe asthma as a restricting factor of their life at school and recreational activities ${ }^{(22)}$. The present study indicated that asthmatic children showed a poor level of physical domain compared to non- asthmatic; however, the daily living of asthmatic children is negatively affected by asthma symptoms and dependency on medication. Recurrent symptoms of asthma that need lifelong medication truly have an impact on children's quality of life ${ }^{(13)}$. This effect was revealed in their dissatisfaction with ability to play, sleeping pattern, and daily activities. Several studies have confirmed that the effects of asthma on quality of life, as reported by El- Fetouh et al (2009) who found that $73.0 \%$ children from North Africa were considered to be handicapped in their everyday activities always or most of the time because of asthma. (10). In addition, Jordanian as well as Taiwanese asthmatic children reported decreased exercise endurance and restrictions in relation to running and playing with friends. ${ }^{(23,24)}$ Furthermore, Gent et al (2007) reported that scores of quality of life in children with a diagnosed asthma was lower than in children with undiagnosed asthma for all domains. (25)

The psychosocial and environmental domains did not greatly differ in asthmatic children from non-asthmatic children included in this study. This could 
be interpreted on the highlight of the asthma.(27)

phenomena of the children belonging to lower socioeconomic class experience more life stressors ${ }^{(26)}$. However; nearly half of the encountered study participants belonged to the low middle class and around one quarters are belonging to the low social class in asthmatic and nonasthmatic children. Furthermore, a positive correlation was found between the socioeconomic class of asthmatic children and their scores of the environmental domain.

The grade of asthma was negatively correlated with the scores of the three quality of life domains, which is in agreement with Chapman (2005) who reported that quality of life is roughly affected by the severity of

\section{Conclusion and recommendations:}

In conclusion, suffering from bronchial asthma negatively affects the children's quality of life, especially the components of

physical domain namely sleeping pattern, as well as limited daily activities due to suffering from pain and dependency on treatment. It is recommended that asthmatic children need to be provided with information regarding healthy behaviors and measures to reduce restrictions on daily activities. In addition, further researches are required to explore the quality of life among asthmatic children in relation to the perception of their caregivers and health care providers. 
Table 1: Distribution of studied children according toQ their Socio-demographic characteristics

\begin{tabular}{|c|c|c|c|c|c|c|}
\hline \multirow[t]{2}{*}{ Items } & \multicolumn{2}{|c|}{$\begin{array}{c}\text { Non-asthmatics } \\
\text { children } \\
\mathrm{N}=196\end{array}$} & \multicolumn{2}{|c|}{$\begin{array}{l}\text { Asthmatics children } \\
\qquad \mathbf{N}=196\end{array}$} & \multirow[t]{2}{*}{$\mathrm{X}^{2}$} & \multirow[t]{2}{*}{$\mathbf{P}$} \\
\hline & No & $\%$ & No & $\%$ & & \\
\hline \multicolumn{7}{|l|}{ Age } \\
\hline Preschool (3 - ) & 75 & 36.3 & 90 & 45.9 & \multirow{2}{*}{2.3} & \multirow{2}{*}{0.14} \\
\hline School (6-12) & 121 & 61.7 & 106 & 54.1 & & \\
\hline \multicolumn{7}{|l|}{ Gender } \\
\hline Male & 125 & 63.7 & 112 & 57.1 & \multirow{2}{*}{1.53} & \multirow{2}{*}{0.128} \\
\hline Female & 71 & 36.2 & 83 & 42.3 & & \\
\hline \multicolumn{7}{|l|}{ Residency area } \\
\hline Urban & 150 & 76.5 & 145 & 73.6 & \multirow{2}{*}{1.29} & \multirow{2}{*}{0.255} \\
\hline Rural & 41 & 20.9 & 52 & 26.5 & & \\
\hline \multicolumn{7}{|l|}{ Socio-economic level } \\
\hline High middle social class & 49 & 25 & 69 & 35.2 & \multirow{3}{*}{5.2} & \multirow{3}{*}{0.072} \\
\hline Low middle social class & 93 & 47.4 & 85 & 43.4 & & \\
\hline Low social class & 54 & 27.5 & 42 & 21.4 & & \\
\hline
\end{tabular}

Table 2: Distribution of asthmatic children according to the severity of asthma

\begin{tabular}{|l|c|c|}
\hline Severity of asthma & Number & $\%$ \\
\hline Mild intermittent & 125 & 63.8 \\
\hline Mild persistent & 37 & 18.9 \\
\hline Moderate persistent & 21 & 10.7 \\
\hline Severe persistent & 13 & 6.6 \\
\hline
\end{tabular}




\begin{tabular}{|c|c|c|c|c|c|c|c|c|c|}
\hline & $a$ & 8 & 8 & 8 & & 8 & 8 & 8 & 8 \\
\hline & $x$ & $\stackrel{\infty}{\sim}$ & $\ddot{\sim}$ & $\tilde{\sigma}$ & & 8 & অ & $\mathbb{N}$ & סo \\
\hline & 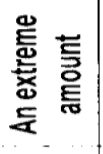 & $\begin{array}{l}\overline{0} \\
\stackrel{8}{8} \\
\stackrel{0}{-}\end{array}$ & $\frac{\bar{a}}{\frac{0}{6}}$ & $\stackrel{\text { a }}{\stackrel{a}{*}}$ & 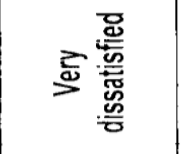 & $\underbrace{\text { in }}_{\text {을 }}$ & 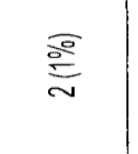 & $\begin{array}{l}\bar{a} \\
\text { in } \\
0 \\
\equiv \\
=\end{array}$ & $\begin{array}{l}\bar{a} \\
\text { in } \\
0 \\
\end{array}$ \\
\hline 要 & 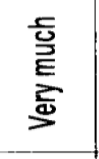 & $\begin{array}{l}\frac{0}{8} \\
0 \\
\frac{\infty}{\infty} \\
\infty\end{array}$ & $\begin{array}{l}\bar{a} \\
\stackrel{0}{0} \\
0 \\
\frac{0}{\square} \\
\square\end{array}$ & $\begin{array}{l}\overline{8} \\
80 \\
\frac{1}{5} \\
8\end{array}$ & 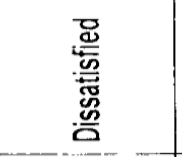 & 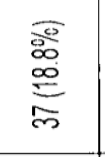 & $\begin{array}{l}\bar{a} \\
\text { io } \\
\text { on } \\
\text { on }\end{array}$ & $\begin{array}{l}\bar{\infty} \\
\infty \\
\infty \\
\stackrel{\infty}{0} \\
m\end{array}$ & 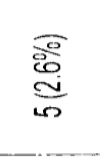 \\
\hline 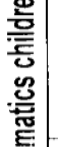 & 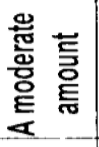 & $\begin{array}{l}\text { a } \\
\text { i } \\
\frac{9}{1}\end{array}$ & $\begin{array}{l}\frac{0}{8} \\
\infty \\
\frac{D}{0} \\
\text { o }\end{array}$ & $\begin{array}{l}\overline{0} \\
\text { on } \\
\frac{m}{0} \\
\frac{0}{0}\end{array}$ & 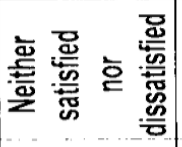 & 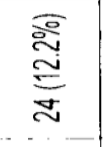 & $\begin{array}{l}\frac{0}{0} \\
\infty \\
0 \\
0 \\
m\end{array}$ & $\frac{a}{2}$ & 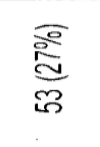 \\
\hline 害 & 墨 & 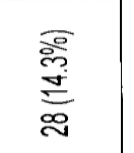 & 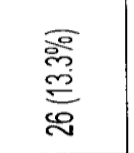 & $\begin{array}{l}\frac{8}{80} \\
\frac{8}{i 5}\end{array}$ & 惫 & 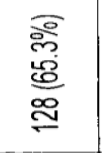 & 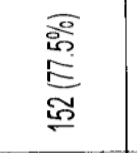 & 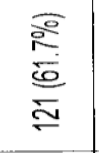 & $\begin{array}{l}\bar{a} \\
\text { ì } \\
\tilde{0} \\
\stackrel{\Xi}{\Xi}\end{array}$ \\
\hline & $\begin{array}{l}\overline{\bar{T}} \\
\text { 芯 } \\
\text { 定 }\end{array}$ & 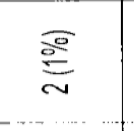 & $=\begin{array}{l}\overline{8} \\
\stackrel{8}{0} \\
0\end{array}$ & 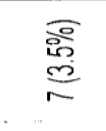 & 胥 & $\frac{\sqrt{a}}{\stackrel{d}{d}}$ & $\frac{\sqrt{8}}{0}$ & $\frac{\bar{a}}{\frac{\dot{d}}{\infty}}$ & $\begin{array}{l}=\overline{8} \\
0 \\
0\end{array}$ \\
\hline & 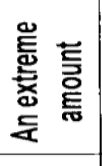 & 응 & $\frac{\bar{g}}{0}$ & $\frac{\bar{g}}{0}$ & 兽 & $\frac{\bar{g}}{0}$ & $\begin{array}{l}\overline{\bar{g}} \\
\stackrel{0}{0} \\
\frac{0}{n}\end{array}$ & $\frac{\overline{8}}{0}$ & 응 \\
\hline 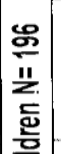 & 臭 & $\begin{array}{l}\text { बूं } \\
\text { ले } \\
\frac{n}{n}\end{array}$ & 용 & $\begin{array}{l}\text { a } \\
\text { in } \\
\text { o } \\
\frac{9}{0}\end{array}$ & 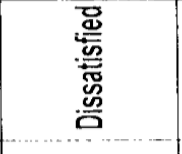 & $\frac{\overline{0}}{0}$ & $\frac{\bar{a}}{\frac{d}{d}}$ & $\begin{array}{l}\frac{a}{8} \\
0 \\
0 \\
=\end{array}$ & $\frac{\overline{8}}{8}$ \\
\hline 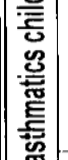 & 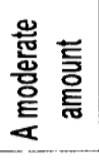 & $\begin{array}{l}\text { 을 } \\
\frac{\text { ñ }}{n}\end{array}$ & 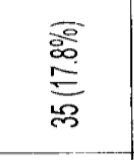 & $\begin{array}{l}\bar{a} \\
0 \\
0 \\
0 \\
\frac{0}{n} \\
0\end{array}$ & 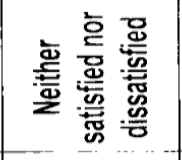 & 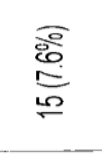 & $\frac{\overline{0}}{\bar{a}}$ & $\begin{array}{l}\frac{5}{8} \\
\frac{8}{5} \\
\frac{5}{2}\end{array}$ & 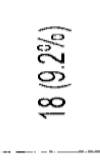 \\
\hline 竞 & 墨 & $\begin{array}{l}\bar{a} \\
\stackrel{0}{e} \\
\stackrel{0}{0}\end{array}$ & 이 & $\underset{\approx}{\stackrel{\bar{\Xi}}{\Sigma}}$ & 总 & 号 $\frac{\bar{a}}{\frac{a}{\sigma}}$ & 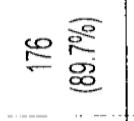 & $\underset{0}{\stackrel{\bar{a}}{\sim}}$ & s: \\
\hline & 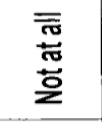 & 邑总 & 횽 & $\frac{\bar{a}}{\stackrel{\square}{a}}$ & 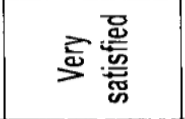 & 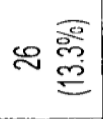 & $\begin{array}{l}\frac{0}{8} \\
\stackrel{0}{0} \\
\frac{10}{n}\end{array}$ & $\frac{\text { 용 }}{\frac{\mathrm{s}}{i}}$ & 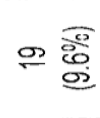 \\
\hline & 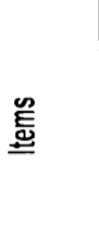 & 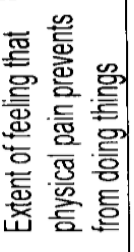 & 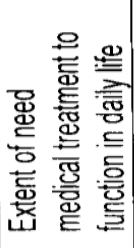 & 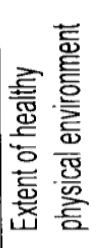 & & 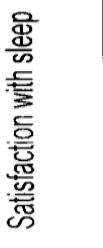 & 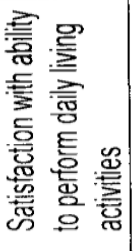 & 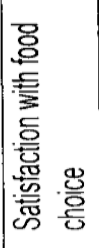 & 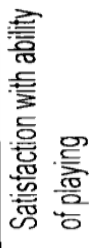 \\
\hline
\end{tabular}


Table 4: Quality of life difference between asthmatic and non-asthmatic children

\begin{tabular}{|c|c|c|c|c|c|c|}
\hline \multirow[t]{2}{*}{ QOL domains } & \multicolumn{2}{|c|}{$\begin{array}{c}\text { Asthmatic } \\
\mathrm{N}=196\end{array}$} & \multicolumn{2}{|c|}{$\begin{array}{c}\text { Non- asthmatic } \\
\mathrm{N}=196\end{array}$} & \multirow[t]{2}{*}{$\begin{array}{l}\text { Odds ratio } \\
\text { (Cl 95\%) }\end{array}$} & \multirow[t]{2}{*}{$\mathbf{P}$} \\
\hline & $\mathbf{N}$ & $\%$ & $\mathbf{N}$ & $\%$ & & \\
\hline \multicolumn{7}{|l|}{ Physical domain } \\
\hline Good & 162 & 82.6 & 189 & 96.4 & \multirow{2}{*}{$\begin{array}{c}0.18 \\
(0.076-0.41)\end{array}$} & \multirow{2}{*}{$0.0001^{*}$} \\
\hline Poor & 34 & 17.3 & 7 & 3.5 & & \\
\hline \multicolumn{7}{|l|}{$\begin{array}{l}\text { Psychosocial } \\
\text { domain }\end{array}$} \\
\hline Good & 164 & 83.6 & 174 & 88.7 & \multirow{2}{*}{$\begin{array}{c}0.64 \\
(0.36-1.2)\end{array}$} & \multirow{2}{*}{0.14} \\
\hline Poor & 32 & 16.3 & 22 & 13.0 & & \\
\hline \multicolumn{7}{|l|}{$\begin{array}{l}\text { Environmental } \\
\text { domain }\end{array}$} \\
\hline Good & 182 & 92.8 & 170 & 86.7 & \multirow{2}{*}{$\begin{array}{c}0.93 \\
(0.53-1.63)\end{array}$} & \multirow{2}{*}{0.7} \\
\hline Poor & 30 & 15.3 & 26 & 13.3 & & \\
\hline
\end{tabular}

* Significant

Table 5: Correlation of level of quality of life with socio-economic class and degree of asthma among asthmatic children

\begin{tabular}{|l|c|c|c|c|}
\hline \multirow{2}{*}{ Quality of life domains } & \multicolumn{2}{|c|}{ Socio-economic class } & \multicolumn{2}{c|}{ Severity of Asthma } \\
\cline { 2 - 5 } & $\mathbf{r}$ & $\mathbf{P}$ & $\mathbf{r}$ & $\mathbf{P}$ \\
\hline Physical domain & 0.057 & 0.204 & -0.33 & $0.000^{\star}$ \\
\hline Psychosocial domain & 0.066 & 0.195 & -0.16 & $0.025^{\star}$ \\
\hline Environmental domain & 0.23 & $0.000^{*}$ & -0.157 & $0.028^{\star}$ \\
\hline
\end{tabular}

* Significant 


\section{REFERENCES}

1. Braman SS. The global burden of asthma. Chest, 2006;130:4S-12S

2. Global Initiative for Asthma. Global Strategy for Asthma Management Prevention. NIH Pub. No 02-3659, January 1995. Updated 2007. cited 2008 Oct 9. Available from: www. ginasthma.com.

3. Anzhela V. Glushkova1, Andrej M. Grjibovski. Prevalence and Correlates of Asthma Among Children in Central St. Petersburg, Russia: Crosssectional Study. Croat Med J, 2008;49:741-50

4. Lerma B, Chirivella FJ, Peñuelas I, Guerra C, Lugo F, Ontoso I et al. High Prevalence of Asthma and Allergic Diseases in Children Aged 6 and 7 Years From the Canary Islands: The International Study of Asthma and Allergies in Childhood. J Investig Allergol Clin Immunol, 2009; 19(5): 383-90.

5. Masjedi M, Fadaizadeh $\mathrm{L}$, Prevalence and Severity of Asthma Symptoms in Children of Tehran. Iranian Journal of Allerg. Asthma and Immunology, 2004; 3 (1): 25-30.

6. Khedr S. Epidemiological allergological and immunological study of bronchial asthma in Egypt. Report submitted to WHO regional office, November 1998.

7. Georgy V, Fahim HI, Gaafary M. E, Walters S. Prevalence and socioeconomic association of asthma and allergic rhinitis in Northen Africa. Eur Respir L, 2006; 28: 756- 62.

8. Sennhauser $\mathrm{FH}$, Braun-Fahrländer $\mathrm{C}$, Wildhaber $\mathrm{JH}$. The burden of asthma in children: a European perspective. Paediatr Respir Rev, 2005;6:2-7
9. Annett RD. Assessment of health status and quality of life outcomes for children with asthma. J Allergy Clin Immunol ,2001; 107: S473-81

10. Abou- El- Ftouh M, Yassine N, Benkheder A, Bouacha H, Nafti S, Taright $S$, et al. Paediatric asthma in North Africa: the Asthma Insights and Reality in the Maghreb (AIRMAG) study. Respiratory Medicine, 2009; 103: S2-S21-S29

11. Masoli M, Fabian D, Holt S, Beasley R. Global Burden of Asthma, Global Initiative for Asthma, 2004; URL: www.Ginastha.com retrieved at 4/2/2009.

12. Juniper EF. How important is quality of life in pediatric asthma? Pediatr Pulmonol Suppl, 1997; 15: 17-21.

13. Alexandra S, Endre C. Bronchial asthma and the short-term quality of life: follow-up study of childhood bronchial asthma in Hungary. Pediar Allergy Immunol, 2004; 15: 539-44.

14. Jacqueline $R$, Rosenzweig $C$, Edwards L, Lincourt W, Dorinsky P, ZuWallack $R L$. The relationship between health-related quality of life, lung function and daily symptoms in patients with persistent asthma. Respir Med, 2004; 98: 1157-65.

15. Singh M, Mathew JL, Malhi $P$, Naidu AN, Kumar L. Evaluation of quality of life in Indian children with bronchial asthma using a disease specific and locally appropriate questionnaire. Act Pediatr Scand, 2004; 93: 554-5.

16. Fleiss J. Statistical methods for rates and prportions, $2^{\text {nd }}$ edition, John Wiley\& Sons, 1981, ISBN 0-47106428-9. pp. 44- 52.

17. Fahmy S, EL Sherbiny A. Determining Simple Parameters for Social Classification for Health Research. Bulletin of High Institute of Public 
Health, 1983; 13 (5): 95-107.

18. National Heart, Lung and Blood Institute. National Asthma Education and Prevention Program. Expert Panel Report 3: Guidelines for the Diagnosis and Management of Asthma. Washington DC: Department of Health and Human Services; 2007; 122-40.

19. World Health Organization, Geneva. Measurement of quality of life in children. Report of WHO, London UK 1994.

20. The World Health Organization Geneva. Quality of Life (WHOQOL)BREF. 1994

21. Boran $P$, Tokuç G, Pişgin B, Öktem $S$. Assessment of quality of life in asthmatic Turkish children. The Turkish Journal of Pediatrics, 2008; 50: 18-22

22. Gabe J, Bury M Ramsay R Living with asthma: the experiences of young people at home and at school. Social Science and Medicine, 2002; 55: 1619-33.

23. Chiang L. C, Hung J. L, Lu C. M. A study of predisposing factors and selfmanagement behaviors of schoolage children with asthma and the impact of summer asthma camp. The Journal of Nursing Research, 1999; 7(4): 307-321.

24. Al-Akour N, Khader Y. Quality of life in Jordanian children with asthma. International Journal of Nursing Practice, 2008; 14: 418-26.

25. Gent R, Essen L, Maroeska M, Kimpen J, Ent C. et al Quality of life in children with undiagnosed and diagnosed asthma. Eur $\mathrm{J}$ Pediatr, 2007; 166:843-8.

26. Chen E, Hanson M, Paterson L, Griffin M., Walker H, Miller G. Socioeconomic status and inflammatory processes in childhood asthma: The role of psychological stress. J Allergy Clin Immunol, 2006;117:1014-20.

27. Chapman K.R. Impact of 'mild' asthma on health outcomes: findings of a systematic search of the literature. Respiratory Medicine, 2005; 99: 1350-62 